\title{
Selected questionnaire methods studying the quality of life
}

\author{
Anna Kłak ${ }^{1}$ Magdalena Mińko², Dorota Siwczyńska³, Bolesław Samoliński ${ }^{1}$ \\ ${ }^{1}$ Department of Prevention of Environmental Hazards and Allergology, Medical University of Warsaw, Warsaw, Poland \\ Head of the Department: Prof. Bolesław Samoliński MD, PhD \\ 2Department of Health Care, Medical University of Warsaw, Warsaw, Poland \\ Head of the Department: Piotr Tyszko MD, PhD \\ ${ }^{3}$ Collegium of Socio-Economics, Warsaw School of Economics, Warsaw, Poland \\ Dean of Collegium: Prof. WSE Joachim Osiński PhD
}

Postep Derm Alergol 2015; XXXII (3): 210-215

DOI: $10.5114 /$ pdia.2015.48047

\begin{abstract}
The scientific literature is full of numerous reports dealing with the quality of life of patients suffering from different diseases. The aim of the study is to present a set of questionnaires, which are used to study the quality of the patient's life, the questionnaires, which are the most popular in Poland and all over the world as well as those which concern the children's allergy. Increasingly, the research deals with the objective and subjective feelings of patients about their condition. Currently, the European Union's priority is to improve the quality of life of patients suffering from chronic non-communicable diseases. The studies on the quality of life are an interdisciplinary area, combining the clinical significance and the psychological aspects of medical care.
\end{abstract}

Key words: quality of life, questionnaire methods, medical sciences, allergies.

\section{Introduction}

Quality of life was defined by the World Health Organization (WHO) as 'an individual's perception of their position in life in the context of the culture and value systems in which they live, and in relation to their goals, expectations, standards and concerns' [1]. The Health Related Quality of Life (HRQL) refers to an individual or the perception of the influence of an illness and its treatment on the quality of life and the functioning of an individual. The HRQL is based on three components: social, psychological and physical ones [1]. The foundation for the concept of quality of life is the definition of health by WHO which is as follows: 'a state of complete physical, mental and social well-being and not merely the absence of disease' [1]. Although the concept of quality of life is difficult to define, it is an essential element of the functioning of every individual. It is a multidimensional concept where every dimension influences general life satisfaction, including satisfaction with health, housing conditions, employment, personal and family safety, interpersonal relations, education and rest. In terms of health care, quality of life refers to those aspects which directly concern health of an individual [2].
Currently, interest in patients' quality of life is increasing, thus the subject of quality of life is becoming more and more popular. Scientific publications are abundant in numerous reports on the quality of life of patients suffering from various diseases. Patients' objective and subjective perception of their medical condition is more and more often examined. At present, it is an European Union (EU) priority to increase quality of life of patients who suffer from chronic non-communicable diseases. Patients report a number of problems concerning their general activity and the deterioration of HRQL. Therefore, in terms of health measurement in a particular population, it is important to understand that patients' quality of life is as important as clinical parameters. The research in quality of life expresses a holistic approach towards a patient and it is of significant importance in the case of chronic diseases, where it may constitute a main dependent variable, next to survival time, in the assessment models of effectiveness of treatment and health care [3]. Nonetheless, traditional research focuses mainly on the assessment of the influence of a therapy on the control over symptoms and the frequency of the occurrence

Address for correspondence: Anna Kłak MSc, Department of Prevention of Environmental Hazards and Allergology, Medical University of Warsaw, 1 a Banacha St, 02-097 Warsaw, Poland, phone: +48 2259920 39, e-mail: anna.klak@wum.edu.pl, klak.anna@o2.pl Received: 23.05.2014, accepted: 10.09.2014. 
of complications, whereas the influence of a therapy on quality of life is far less frequently analysed. In the last 20 years the assessment of the quality of life of patients suffering from chronic diseases was subject to analysis. This analysis showed that often some changes which are insignificant from the perspective of medical personnel, may influence significantly patients or their families. At the same time, other changes which doctors perceive as important from the perspective of both patients' health and personal circumstances, may not be observed by the patients. For instance, foreign literature abounds in many reports on asthma as a clinical unit and the importance of research in the quality of life of asthmatics [4-6]. Oğuzturk et al. indicated that the quality of life of asthmatics deteriorated with age [7]. In their research Hazel et al. demonstrated the deficit in the quality of life in relation to the age of those surveyed [8]. With reference to the research on the influence of gender on the quality of life of asthmatics, he stated that being a female influences the deterioration of the results of the measurement of quality of life with the use of the Euro - Quality of Life Questionnaire (EQ-5D).

The aim of the study is to present a set of the questionnaires, which are used to study the quality of the patient's life.

The detailed aims are: to present the questionnaires which are the most popular in Poland and all over the world; to analyse and evaluate the questionnaires which concern the children's allergy.

\section{Methods for quality of life research}

In terms of psychological assessment, quality of life can be studied with the use of various methods. Qualitative and multifactor research enables precise evaluation of the patient's self-being and it makes quantitative assessment possible. Nonetheless, this type of studies is labour-intensive [9]. Quality of life can also be measured with a questionnaire. This method enables a quantitative result which can be compared with research conducted in other groups of patients. Generic (general) and individual (specific) tools are most frequently used in quality of life measurement [10]. Generic tools involve health profiles and norms of the utility of a health status. Thus, they make assessment of every patient's quality of life possible. They enable the measurement of all substantial aspects of quality of life. Utility norms show preferences of those surveyed towards a certain health status, as the same illness might differently influence an individual's life. The measurement of quality of life might be conducted by means of a test without the use of multifaceted value scales. Generic tools are characterized by slight sensitivity of measurements, i.e. opportunity to detect slight differences of clinical importance.

\section{Questionnaire as a tool for quality of life measurement}

An analysis of quality of life performed on the basis of a questionnaire allows research in a much bigger study group that in the case of multifactor research. In the course of the study, a psychologist might act as a consultant. However, during the study his presence is not as important as it is in the process of questionnaire development and results analysis [9].

In terms of terminology, questionnaires can be divided into general and specific ones [9]. The former are used to assess interdependencies between patient's health status and numerous factors, such as family relations, emotional status, professional activity, etc., whereas the latter are further divided into two categories. The first category of specific questionnaires focuses on the analysis of specific domains of a patient's functioning (domain-specific). The other category analyses factors which result from the disease itself (disease-specific). This category is important due to the possibility it offers to assess a patient's self-being, the degree of the intensification of symptoms, the influence of a disease on a patient's emotional status and everyday social and professional activity [11].

\section{Examples of questionnaires}

\section{St. George's Respiratory Questionnaire}

St. George's Respiratory Questionnaire (SGRQ) is a questionnaire which analyses the influence of respiratory diseases on everyday activity of a patient. It is to be self-administered by patients, especially those suffering from asthma and chronic obstructive pulmonary disease. The questionnaire consists of three parts. The first part analyses conditions, such as sputum expectoration, frequency of cough, the frequency and duration of wheezing and shortness of breath, etc. The second part of the questionnaire concerns physical activity, in particular limitations of such an activity, being the result of a disease. The last part of the questionnaire analyses the influence of the disease on everyday functioning of a patient in a society (social and professional activity, side effects, demand for medication) [9]. This tool does not focus on the symptoms of depression or patient's anxiety but on the influence of a disease on patient's psychological and social functioning [12].

\section{Asthma Severity Scale}

This questionnaire focuses on aspects related to the control of the course of disease. It was developed in two versions: for children and for adults with the difference in the scale length. For adults there is a 7-point scale, whereas for children the scale is shorter. This tool is recommended in the research which analyses subjective assessment of disease severity [11]. 


\section{Living with Asthma Questionnaire (LWAQ)}

In order to assess the course of treatment of asthma in adults, Hyland developed a questionnaire which consists of questions concerning sport, sleep disorders, professional work and leisure time [13]. This questionnaire assesses patient's activity. It takes about 20 min to complete it and the questionnaire can be filled in by a doctor in the course of medical history completion. It is considered to be valuable in long-term research.

\section{Outcome Measures in Ambulatory Care (Asthma and Diabetes) (OMAC)}

This tool enables the analysis of the control over the frequency of symptoms and complications [14]. Moreover, it can be used to conduct subjective assessment of the severity of a disease through the study of pain, sleep disorders, patient's self-being and psycho-social aspects. Nonetheless, the tool requires further research into its usefulness.

\section{Asthma Quality of Live Questionnaire (AQLQ)}

This questionnaire was developed by Professor Elizabeth Juniper of McMaster University in Canada [15]. It consists of 32 questions to be completed individually by a respondent or by a doctor in the course of medical history completion. Its aim is to assess the influence of a therapeutic process on asthmatic's everyday activity. With the use of a few-point scale the following aspects can be assessed: the intensity of physical activity, avoidance of factors influencing shortness of breath, frequency of symptoms at night, anxiety, influence of the disease on patient's everyday activity in a society [11]. The questionnaire is recommended for clinical research. Professor Juniper also developed AQLQ for children which was used in numerous studies all over the world.

\section{Euro - Quality of Life Questionnaire (EQ-5D)}

This questionnaire is used for patients over the age of 12. Its aim is to analyse the health status considering five categories: self-care, mobility, usual activities (work, house duties, learning, leisure, family), anxiety/depression and pain/discomfort. The questionnaire was divided into two parts. The first part is based on the abovementioned categories of health status assessment (EQ Index), whereas the second part includes the VAS scale where a respondent assesses his health status (EQ-VAS) [16].

\section{Short Form Health Survey (SF-36)}

The scale consists of 36 questions and 8 areas. This questionnaire analyses a functional health and wellbeing profile at an 8-point scale together with psychometric assessment based on a respondent's physical and mental health status. Quality of life in terms of physical health status is measured with the following factors: physical functioning, pain, general health status. Quality of life in terms of mental health is measured with the following factors: vitality of the functioning in a society, emotional and mental status. SF-36 proved to be useful in research in a general and specific population, when comparing relative severity of a disease and diversified health services provided in the course of treatments. SF-36 was developed to fulfil minimal psychometric standards necessary to compare a group. Health concepts were chosen from 40 concepts included in the Medical Outcomes Study (MOS) (Stewart \& Ware, 1992). They represent the most frequently measured concepts commonly used in the research concerning health. Certain elements of the questionnaire assess health status indicators, such as the preservation of functions and dysfunctions, anxiety and wellbeing, objective and subjective health status assessment and positive and negative self-assessment of general health status.

\section{The problem of quality of life assessment in children suffering from allergy}

In the case of children suffering from allergy, the questionnaires studying the quality of life are limited. The problem is that there are no general questionnaires which assess the quality of life of an allergic child. Although there is a wide choice of questionnaires concerning a specific disease entity, the development of general assessment of allergy in children is a difficult task. In order to assess the quality of life of children suffering from atopic dermatitis or eczema, the following questionnaires can be used: SCORAD, Nottingham Eczema Severity Score (NESS), Children's Dermatology Life Quality Index (CDLQI), Dermatitis Impact (DFI), Childhood Atopic Dermatitis Impact Scale (CADIS), Parents' Index of Quality of Life in Atopic Dermatitis (PIQoL-AD), Childhood Impact of Atopic Dermatitis, Quality of Life in Primary Caregivers of Children with Atopic Dermatitis and Self-Administered Eczema Area and Severity Index (SA-EASI). For the analysis of quality of life of a child suffering from asthma, Asthma Severity Scale or Paediatric Asthma Quality of Life Questionnaire (PAQLQ) can be used. PAQLQ was adjusted to Polish conditions [17-19] in 2004 by Madaj, among other researchers [20]. The author of the research evaluated this tool positively. In particular, she pinpointed its sensitivity and specificity. For the assessment of the quality of life of parents/carers of an ill child, the following questionnaires are used: The Family Support Scale and Family Impact Scale. Also the General Health Questionnaire and Children's Health Questionnaire can be used to study the general quality of life of a child. On the basis of the PubMed database analysis, it can be assumed that none of these questionnaires was used in Poland to assess the quality of life of children suffering from allergy. Although both questionnaires were adjusted to Polish conditions, they were used for general quality 
of life assessment [21] or the quality of life assessment for social diseases [22-25]. One study based upon the Children's Health Questionnaire involved children suffering from asthma [26]. However, this questionnaire is addressed to children over the age of 10 , whereas the biggest percentage of children suffering from allergy in Poland are in the group of 6- and 7-year-olds (more than 30\%) [27]. Therefore, in the case of the assessment of quality of life of a child suffering from allergy in the age of 6-7, it might be worth considering whether to use a general questionnaire, such as the General Health Questionnaire or Children's Health Questionnaire, which are not specific to allergic diseases, or to use simultaneously a few specific questionnaires for particular disease entities (e.g. PAQLQ, Nottingham Eczema Severity Score (NESS)). The fact that there is no questionnaire assessing the quality of life of a child suffering from allergy seems to be a serious issue.

\section{Discussion}

Out of 549 scientific reports concerning the SGRQ questionnaire available in PubMed database only 5 were developed by Polish scientists. The key fact is that the oldest of these reports (1999) concerned the adjustment of the Polish version of St. George questionnaire to patients with asthma [28]. Kuźniar states that the reliability of the questionnaire was high with the Cronbach's $\alpha$ coefficient over 0.75 for the totality and for particular domains. Significant correlations of the following parameters were shown: spirometry, intensification of symptoms, self-assessment of health status and the level of depression, and quality of life. Test-retest, stability and short time of the questionnaire completion were confirmed. A psychometric analysis proved that the shortened Polish version of SGRQ is equivalent to the original version of SGRQ [28]. The other 3 publications concern the use of SGRQ for the assessment of chronic obstructive pulmonary disease symptoms, changes in mucous membrane, nose rinsing and eicosanoid cells [29], AZD9668, inhibitor for the elastase of neutrophilles and budesonide/formoterol in patients suffering from chronic obstructive pulmonary disease [30]. Thus, SGRQ is a tool for the assessment of quality of life of those suffering from respiratory diseases [31]. With the reference to other questionnaires, the Short Form Health Survey is the most frequently quoted questionnaire in the PubMed database (out of 10329 reports, 43 were developed by Polish researchers), whereas the Outcome Measures in Ambulatory Care (Asthma and Diabetes) is the least frequently quoted tool, as it is referred to in one report only. Next places in terms of the frequency of quotation are taken by the Euro - Quality of Life Questionnaire (out of 1891 reports, 2 were written by Polish scientists), Nottingham Health Profile (out of 1013 reports, one was written by Polish researchers), (WHOQOL) - BREFF (out of 646 re- ports, 8 were written by Polish researchers), Asthma Severity Scale (out of 639 reports, none was written by Polish researchers), the Karnofsky Performance Index (out of 571 reports, none was written by Polish researchers), Asthma Quality of Live Questionnaire (out of 229 reports, 5 were written by Polish researchers), Quality of Life in Epilepsy Inventory (out of 201 reports, none was written by Polish researchers) and Living with Asthma Questionnaire (out of 15 reports, none was written by Polish researchers). The oldest of the aforementioned questionnaires is the Karnofsky Performance Index (1977), Nottingham Health Profile (1986) and Asthma Severity Scale (1988). The remaining questionnaires come from the last decade of the $20^{\text {th }}$ century. The World Health Organization Quality of Life (1998) is a relatively young questionnaire. Besides the St. George's Respiratory Questionnaire, the following questionnaires were adjusted to Polish conditions: AQLQ, for which a version for children - Paediatric Asthma Quality of Life Questionnaire (PAQLQ) - was also developed, and a questionnaire for the carers of asthmatic children - Caregivers' Paediatric Asthma Quality of Life Questionnaire (CPAQLQ) [32]. SGRQ questionnaire is available in Danish, Dutch, English, Finnish, French, German, Greek, Italian, Norwegian, Portuguese, Spanish, Swiss and Thai. A shortened version of the questionnaire is also available in the Polish language version; however, the translation was done by the MAPI Research Institute (www.mapi-institute.com), which does not guarantee successful adaptation to Polish life conditions. The SGRQ questionnaire consists of two parts. The first part (questions 1-7) refers to the frequency of respiratory symptoms. This part cannot be construed as an epidemiologic tool but as a subjective assessment of patient's breathing problems. The second part (questions $8-14)$ refers to the patient's current health status, e.g. physical activity. The assessment of the influence covers a range of disorders in psychosocial functions. The validation of the questionnaire showed that physical activity refers to some extent to the respiratory system but it also correlates quite strongly with the performance of physical activities, shortness of breath in the course of usual activities and mood disturbances [33]. In the case of AQLQ, having validated the questionnaire in many countries, the authors proved very strong characteristics of the measurement [34]. Moreover, they pinpointed many advantages of AQLQ, the most important of them being: perfect test-retest reliability, sensitivity, specificity, correlations between the clinical health status and patient's subjective perception [35]. High diagnostic sensitivity is also an advantage of SF-36, therefore it can be applied at an early stage of a disease. The aforementioned questionnaire is one of the most important tools used in somatic diseases, as it is helpful in the development of specific questionnaires [34]. Advantages of SGRQ are test-retest, which provides coherent results over a short period of time in a subgroup of stably ill patients, and good adap- 
tation to patients suffering from bronchial diseases [36]. SGQR can differentiate between various levels of health status deterioration in patients with bronchial diseases and it seems to be sensitive to spontaneous changes in the health status within the period of 6 months [36]. Although Wilson proved stability and accuracy of SGRQ with reference to respiratory tract symptoms, he did not show any correlation between the symptoms of the disease and physical activity [36]. The questionnaire is not flawless because the interpretation of the HRQL results remains one of the main barriers to the use of this questionnaire in clinical environment [37]. Wilson argues that the relation between the change in SRGQ results and the change in HRQL result is not of substantial nature [36]. In the case of the NHP questionnaire the situation is similar, as it is advisable to provide the research with additional tools which take into consideration an emotional aspect related to the disease in the case of allergic diseases concerned in this questionnaire [32].

\section{Conclusions}

It seems that the most popular tool for the quality of life research is the Short Form Health Survey, whereas the least quoted questionnaire is the Outcome Measures in Ambulatory Care (Asthma and Diabetes) (OMAC). Questionnaires which were the most frequently used in Poland were (SF-36), (AQLQ), and (WHOQOL) - BREFF. Many questionnaires which are available in other countries have not been adjusted to Polish conditions. On the basis of the PubMed database it can be asserted that quite a significant number of questionnaires assessing quality of life were not analysed in Poland. Therefore, there is a low percentage of the adjustment of foreign questionnaires assessing quality of life to Polish conditions.

Moreover, questionnaires assessing quality of life of children, especially those suffering from allergic diseases, pose a significant problem. There are no questionnaires which study the quality of life of allergic children. In the light of public health, understood in broad terms, every human is perceived from a holistic perspective. Thus, considering the fact that allergy belongs to civilization diseases and affects quite a substantial percentage of the Polish society [33], quality of life of patients suffering from allergy should be given special attention and be thoroughly examined. Thus, the development of a tool which could be a novelty in the area of quality of life research is worth considering.

\section{Conflict of interest}

The authors declare no conflict of interest.

\section{References}

1. Karski J, Słońska Z, Wasilewski B. Promocja zdrowia. Sanmedia, Warsaw 1991; 20-3.
2. Bergner M. Quality of life, health and clinical research. Med Care 1989; 27: 148-9.

3. Majkowicz M, Zdun-Ryżewska A. Ocena jakości życia w zaburzeniach psychicznych. Psychiatria w Praktyce Klinicznej 2009; 2: 100-14.

4. Hyland M. Quality of life assessment in the adult asthma sufferers. J Psychom Res 1991; 35: 99-110.

5. Jones PW; Group at NSQoLS. Quality of life, symptoms and pulmonary function in asthma, long term treatment with nedocromil sodium examined in a controlled multicentre trial. Eur Resp J 1994, 7: 55-62.

6. Molen T. Quality of life in asthma. Europ Respir Rev 1997; 42: 82-4.

7. Oğuzturk O, Ekici A, Kara M, et al. Psychological status and quality of life in elderly patients with asthma. Psychosomatics 2005; 46: 41-6.

8. Hazell M, Frank T, Frank P. Health related quality of life in individuals with asthma related symptoms. Respir Med 2003; 97: 1211-8.

9. Pierzchała W, Farnik-Brodzińska M. Jakość życia i jej ocena u chorych na astmę. Alergia Astma Immunol 1997; 2: 203-6.

10. Sokolnicka H, Mikuła W. Methods of evaluation of the quality of life which have an application in medicine. Med Rodz 2003; 3: 129-31.

11. Bowling A. Measuring disease. Open University Press, Buckingham 1995.

12. Jones P, Qiirk F, Baveystock C. A selfcomplete measure of health status for chronic airflow limitation: The St. George's Respiratory Questionnaire. A Rev Resp Dis 1992; 145: 1321-7.

13. Hyland M, Kenyon C. A scale for assessing quality of life. J Psychom Res 1991; 135: 25-9.

14. Mc. Cool E, Meadows K, Hutchinson A. Outcome measure in ambulatory care: developing measures for asthma and diabetes. A paper presented to the Society for Social Medicine. Health Related Quality of Life Workshop, Sheffield, May 1993.

15. Juniper EF, Guyatt GH, Epstein RS, et al. Evaluation of impairment of health-related quality of life in asthma: development of a questionnaire for use in clinical trials. Thorax 1992; 47: 7-83.

16. Uchmanowicz I, Jankowska B, Banaszek B, et al. The impact of socio-demographic factors on health related quality of life (HRQoL) of patients with astma. Alergologia Info 2010; 5: 57-65.

17. Stelmach I, Podlecka D, Majak P, et al. Validity of the Pediatric Asthma Quality of Life Questionnaire in Polish children. Pediatr Allergy Immunol 2011; 22: 660-6.

18. Trzcieniecka-Green A, Bargiel-Matusiewicz K, WilczynskaKwiatek A. Quality of life and activity of children suffering from bronchial asthma. Eur J Med Res 2009; 14: 147-50.

19. Ziora D, Madaj A, Wieckowka E, et al. Correlation of spirometric parameters taken at a single examination with the quality of life in children with stable asthma. Physiol Pharmacol 2007; 58: 801-9.

20. Madaj A, Ziora D, Kozielski J, et al. Quality of life in paediatric asthma patients - correlations with pulmonary function test. Alergia Astma Immunol 2004; 9: 45-9.

21. Małkowska-Szkutnik A, Tabak I, Mazur J. Application of the Polish version of CHQ-PF28 questionnaire in two population studies carried out in 2003 and 2008. Med Wieku Rozwoj 2010; 14: 246-59.

22. Szkup-Jabłońska M, Karakiewicz B, Grochans E, et al. The effects of lead level in the blood on social functioning in 
children with developmental disabilities. Psychiatr Pol 2011; 45: 713-22.

23. Mazur J, Matkowska-Szkutnik A. Health-related quality of life in 13-year-old Polish adolescents measured by CHQ-PF28 questionnaire in relation to family socioeconomic status in the first year of life. Med Wieku Rozwoj 2010; 14: 260-71.

24. Michalska-Leśniewicz M, Gruszczyński W. Psychological determinants of quality of life in women diagnosed with depressive disorders. Psychiatr Pol 2010; 44: 529-41.

25. Tabak I, Jodkowska M, Oblacińska A. Social determinants of psychological distress in adolescents aged 18 years in Poland. Med Wieku Rozwoj 2008; 12: 569-76.

26. Zejda JE, Brozek GM, Cholewa Z, et al. Prevention of childhood bronchial asthma - needs, abilities, limitations. Wiad Lek 2002; 55: 599-602.

27. Samoliński B, Lipiec A, Raciborski F, et al. Epidemiologia chorób alergicznych w Polsce - doniesienie wstępne. Alergia Astma Immunologia 2007; 12: 12-5.

28. Kuźniar T, Patkowski J, Liebhart J, et al. Validation of the Polish version of St. George's respiratory questionnaire in patients with bronchial asthma. Pneumonol Alergol Pol 1999; 67: 497-503.

29. Piotrowska VM, Piotrowski WJ, Kurmanowska Z, et al. Rhinosinusitis in COPD: symptoms, mucosal changes, nasal lavage cells and eicosanoids. Int J Chron Obstruct Pulmon Dis 2010; 5: 107-17.

30. Kuna P, Jenkins M, O’Brien CD, Fahy WA. AZD9668, a neutrophil elastase inhibitor, plus ongoing budesonide/ formoterol in patients with COPD. Respir Med 2011: 531-9.

31. Kuźniar T, Patkowski J. St. George’s Hospital questionnaire (St. George's Respiratory Questionnaire) as an instrument for quality of life assessment in respiratory tract diseases. Pol Arch Med Wewn 2000; 104: 1-12.

32. Farnik-Brodzińska M, Pierzchała W. Znaczenie badań jakości życia w chorobach alergicznych. Alergologia Współcz 2002; 4: 3-7.

33. Meguro M, Barley EA, Spencer S. Development and validation of an improved, COPD-specific version of the St. George Respiratory Questionnaire. Chest 2007; 132: 456-63.

34. Bąk-Drabik K, Ziora D. Quality of life in chronic obstructive pulmonary disease. Pneumonol Alergol Pol 2004; 72: 128-33.

35. Juniper EF, Buist AS, Cox FM, et al. Validation of a standardized version of the Asthma Quality of Life Questionnaire. Chest 1999; 115: 1265-70.

36. Wilson CB, Jones PW, O'Leary CJ, et al. Validation of the St. George's Respiratory Questionnaire in bronchiectasis. Am J Respir Crit Care Med 1997; 156: 536-41.

37. Ferrer M, Villasante C, Alonso J, et al. Interpretation of quality of life scores from the St Georges. Eur Respir J 2002; 19: 405-13. 